\title{
Qualidade do creme de leite artesanal
}

\section{Quality of handmade milk cream}

\author{
Karoline Mikaelle de Paiva Soares ${ }^{1 *}$; Vilson Alves de Góis ${ }^{2}$; \\ Jean Berg Alves da Silva ${ }^{3}$; Nicholas Morais Bezerra ${ }^{4}$
}

\section{Resumo}

A qualidade e a segurança dos alimentos são importantes temas da atualidade. Neste contexto, o presente trabalho teve por objetivo avaliar a qualidade microbiológica e físico-química de cremes de leite artesanais, conhecidos como cremes do sertão. Assim, foram coletadas amostras de cremes do sertão adquiridas de trinta estabelecimentos comerciais localizados no Rio Grande do Norte. Estas amostras foram submetidas às análises microbiológicas de: contagem padrão em placas de microorganismos aeróbios mesófilos, contagem de Staphylococcus aureus e determinação de número mais provável (NMP) de coliformes totais e termotolerantes; e análises físico-químicas de acidez titulável, teor de gordura e umidade. Verificou-se que todas as amostras apresentaram-se fora dos padrões legais na contagem de mesófilos, onde os valores encontrados foram superiores a $10^{5} \mathrm{UFC} / \mathrm{g}$. Um percentual de $90 \%$ dos cremes de leite avaliados apresentaram contagens de $S$. aureus acima do permitido pela legislação (máximo $10^{2} \mathrm{UFC} / \mathrm{g}$ ). A acidez titulável estava acima do permitido em $90 \%$ dos cremes avaliados. Assim, o creme de leite produzido artesanalmente apresentou baixa qualidade microbiológica e físico-química, portanto o seu consumo pode ocasionar riscos à saúde do consumidor.

Palavras-chave: Creme de leite, microbiologia, qualidade, riscos

\begin{abstract}
The quality and food safety are important issues nowadays. In this context, the present work aimed to evaluate the microbiological and physico-chemical of handmade milk creams, known as cream of the backlands. Thus, samples of creams of the hinterland acquired thirty merchants of Rio Grande do Norte. These samples were subjected to microbiological analysis: standard plate count of mesophilic aerobic micro-organisms, Staphylococcus aureus and determination of the most probable number (MPN) of total and fecal coliforms, and physicochemical analysis of titratable acidity content fat and moisture. It was found that all samples were outside the legal standards in mesophilic count, where the values were greater than $105 \mathrm{CFU} / \mathrm{g}$. A percentage of $90 \%$ of the creams milk showed high counts of S. aureus above those permitted by legislation (maximum $10^{2} \mathrm{CFU} / \mathrm{g}$ ). The acidity was above the allowed $90 \%$ of creams evaluated. Thus, the cream produced by hand showed low microbiological and physicalchemical, so its consumption may cause health risks to the consumer.
\end{abstract}

Key words: Milk cream, microbiology, quality, risk

\footnotetext{
${ }^{1}$ Prof $^{\mathrm{a}}$ do Dept ${ }^{\mathrm{o}}$ de Ciências Animais, Universidade Federal Rural do Semi-Árido, UFERSA, Mossoró, RN. E-mail: karolinemikaelle@hotmail.com

${ }^{2}$ Prof. do Dept ${ }^{0}$ de Agrotecnologia e Ciências Sociais, UFERSA, Mossoró, RN. E-mail: vilsongois@ufersa.edu.br

${ }^{3}$ Prof. do Dept ${ }^{0}$ de Ciências Animais, UFERSA, Mossoró, RN. E-mail: jeanberg@ufersa.edu.br

${ }^{4}$ Prof. da Universidade Potiguar, Mossoró, RN. E-mail: nicholasmb@gmail.com

* Autor para correspondência
} 
O creme de leite é uma emulsão de gordura em leite, produto de composição muito similar a do leite integral, exceto pela alta quantidade de gordura que é adicionada para caracterizar o tipo de creme a ser produzido (GONÇALVES, 2012). O "creme do sertão" é um tipo de creme de leite produzido artesanalmente, sem emprego de processamento térmico, principalmente no Nordeste, sem uma fiscalização efetiva, embora exista um Regulamento Técnico de Identidade e Qualidade de creme de leite estabelecido na Portaria No 147 de 1996, que preconiza seus requisitos microbiológicos e físicoquímicos (BRASIL, 1996).

Os alimentos obtidos por processos artesanais têm grande possibilidade de apresentar contaminação, que pode ocorrer pelo uso de matérias-primas não inspecionadas, utensílios mal higienizados ou contaminados, manipulação por pessoas não treinadas, elaboração em condições impróprias e armazenamento e comercialização em temperatura inadequada, fatores que contribuem para aumentar o risco de causarem enfermidades (DUARTE et al., 2005).

A qualidade microbiológica dos alimentos está relacionada à presença de micro-organismos deteriorantes e agentes patogênicos que comprometem a segurança do produto. A qualidade microbiológica de derivados lácteos pode afetar diretamente a sua qualidade físico-química, já que existem grupos de micro-organismos que, em condições apropriadas, são capazes de fermentar a lactose produzindo ácido lático, aumentando a acidez do produto (PINTO; MARTINS; VANETTI, 2006; JAY, 2005; ORDONEZ, 2005).

O Regulamento Técnico de Identidade e Qualidade de creme de leite estabelece critérios microbiológicos para micro-organismos aeróbios mesófilos (máximo $10^{5} \mathrm{UFC} / \mathrm{g}$ ), Staphylococcus aureus (máximo 10² UFC/g), coliformes totais (máximo $10^{2} \mathrm{NMP} / \mathrm{g}$ ) e coliformes termotolerantes (máximo $10 \mathrm{NMP} / \mathrm{g}$ ) para o creme de leite pasteurizado. Segundo a legislação brasileira, o creme deve ser submetido a um tratamento térmico que pode ser do tipo: pasteurização, esterilização e UHT. O creme do sertão, fabricado de forma artesanal, é produzido com ausência de tratamento térmico.

Os parâmetros físico-químicos exigidos pela legislação brasileira para o creme de leite são a acidez máxima de $0,2 \mathrm{~g}$ de ácido lático por $100 \mathrm{~g}$ de creme e o teor de gordura que varia conforme o tipo de creme (creme leve, creme e creme com alto teor de gordura) e que por sua vez deve ser indicado no rótulo do produto. Além destes requisitos de qualidade, vale ressaltar que os produtos alimentícios devem ser elaborados de acordo com as Boas Práticas de Fabricação (BPF) (BRASIL, 1996; BRASIL, 1997a, 1997b).

Neste sentido, o presente trabalho teve por objetivo avaliar a qualidade microbiológica e físicoquímica do creme de leite artesanal, verificando se este produto atende os requisitos de qualidade estabelecidos pela legislação brasileira.

Foram coletadas 30 amostras (uma amostra de cada estabelecimento - peso médio de aproximadamente 200g) de "cremes do sertão" em 30 estabelecimentos comerciais localizados no estado do Rio Grande do Norte (Mossoró-RN). Os estabelecimentos comerciais foram escolhidos ao acaso.

Após a coleta, as amostras inspecionadas quanto à presença de rótulo informando o tipo creme (classificação em relação ao teor de gordura). Em seguida, foram transportadas em caixas isotérmicas para o Laboratório de Inspeção de Produtos de Origem Animal da Universidade Federal Rural do Semi-Árido (UFERSA), onde foram realizadas as análises microbiológicas, em duplicata. Os resultados foram expressos a partir da média das repetições.

As análises microbiológicas foram realizadas de acordo com a Instrução Normativa No 62 de 26 de Agosto de 2003 do Ministério da Agricultura, Pecuária e Abastecimento (MAPA), incluindo: 
contagem padrão em placas de micro-organismos aeróbios mesófilos, contagem de $S$. aureus e determinação de número mais provável (NMP) de coliformes totais e termotolerantes (BRASIL, 2003). Os resultados das contagens microbiológicas foram expressos em UFC/g, enquanto que as estimativas para coliformes totais e termotolerantes foram expressos em NMP/g. Para cada amostra foram feitas diluições em solução salina peptonada a $0,1 \%$, resultando em cinco diluições variando de $10^{0}$ a $10^{-4}$.

A qualidade físico-química das amostras foi avaliada através da determinação do teor de gordura, acidez e teor de umidade no Laboratório de Tecnologia de Alimentos da UFERSA. Para análise do teor de gordura, utilizou-se uma adaptação do método de Gerber (BSI, 1989). Com auxílio de balança analítica de precisão, pesou-se $10 \mathrm{~g}$ de cada amostra de creme do sertão. Em seguida, adicionouse $40 \mathrm{~mL}$ de água destilada fervente. Transferiu-se $10 \mathrm{~mL}$ da mistura com auxílio de pipeta volumétrica para um butirômetro de Gerber contendo $10 \mathrm{~mL}$ de ácido sulfúrico $\left(\mathrm{d}=1,282 \mathrm{~g} / \mathrm{cm}^{3}\right)$. Adicionou-se 1 $\mathrm{mL}$ de álcool amílico. A centrifugação foi realizada durante cinco minutos e logo após foi realizada a leitura. O resultado foi expresso em g de gordura/ $100 \mathrm{~g}$ de creme (\% de gordura). A acidez titulável e o teor de umidade foram medidos através de metodologia proposta pela AOAC (1990) e os resultados foram expressos, respectivamente, em $\mathrm{g}$ de ácido lático/ $100 \mathrm{~g}$ de creme (\% ácido lático) e $\mathrm{g}$ de umidade/ $100 \mathrm{~g}$ de creme (\% de umidade). As análises físico-químicas foram realizadas em duplicata, sendo os resultados obtidos por média.

A contagem de micro-organismos aeróbios mesófilos variou de 5,02 a 5,89 log UFC/g. A legislação preconiza no máximo $5 \log \mathrm{UFC} / \mathrm{g}\left(10^{5}\right.$ UFC/g). Todas as 30 amostras encontraram-se fora dos padrões legais exigidos pela legislação brasileira (Tabela 1). Por suas características intrínsecas, como alto teor gordura, acidez e atividade de água inferior ao leite in natura, o creme de leite é menos propício ao desenvolvimento de micro-organismos quando comparado ao leite fluido (ORDONEZ, 2005; JAY, 2005). Mortatti et al. (1992) ao pesquisarem microorganismos aeróbios mesófilos em doce de leite produzido artesanalmente, detectaram contagens elevadas destes micro-organismos em 97,4\% das mesmas, apesar do produto analisado possuir baixa atividade de água, o que mostra à associação da contaminação por este grupo de bactérias com a falta de higiene no processo de fabricação, como a manipulação inadequada, citada por Almeida et al. (1995) que encontraram contagens de microorganismos aeróbios mesófilos de até $7 \log$ UFC/ mão em pesquisa com manipuladores de alimentos artesanais.

As elevadas contagens de aeróbios mesófilos detectadas no presente estudo estão associadas provavelmente a contaminação nas diversas etapas da cadeia de produção artesanal do creme do sertão, além da falta de tratamento térmico do produto. Ribeiro Júnior et al. (2012) reportam baixas contagens microbiológicas de aeróbios mesófilos em cremes de leite UHT, observando que apenas 2,38\% das amostras avaliadas apresentaram contagem microbiológica superior ao padrão estabelecido pela legislação brasileira.

Segundo Germano e Germano (2008), a manipulação artesanal pode representar um risco à saúde pública. Um fator agravante deste risco, é que apesar de todos os incidentes envolvendo a ingestão de alimentos contaminados amplamente divulgados pela mídia, a população continua a se utilizar destes serviços, por praticidade ou por acreditar erroneamente que a qualidade de produtos artesanais é superior a dos estabelecimentos comerciais.

Verificou-se ausência de $S$. aureus em três amostras. As contagens de $S$. aureus variaram de 0 a 3,48 $\log$ UFC/g. Segundo o regulamento de qualidade do creme de leite, as contagens de S. aureus devem ser de no máximo $2 \mathrm{log} \mathrm{UFC} / \mathrm{g}$. Um percentual de $90 \%$ das amostras analisadas apresentaram contagens elevadas, acima do permitido pela legislação. Balbini e Butugan 
(2001) em estudo sobre contaminação biológica principais micro-organismos causadores de doenças de alimentos apontam o $S$. aureus com um dos de origem alimentar.

Tabela 1. Médias dos resultados dos parâmetros de qualidade microbiológica e físico-química de cremes de leite artesanais comercializados em 30 estabelecimentos comerciais no Rio Grande do Norte (Mossoró-RN).

\begin{tabular}{|c|c|c|c|c|c|c|c|}
\hline $\begin{array}{c}\text { Estabelecimento } \\
\text { cormercial }\end{array}$ & $\begin{array}{l}\text { Mesófilos } \\
(\operatorname{logUFC/g)}\end{array}$ & $\begin{array}{c}\text { S. aureus } \\
(\operatorname{logUFC/g)}\end{array}$ & $\begin{array}{l}\text { Coliformes a } \\
35^{\circ} \mathrm{C} \text { NMP/g }\end{array}$ & $\begin{array}{l}\text { Coliformes a } \\
45^{\circ} \mathrm{C} \text { NMP/g }\end{array}$ & $\begin{array}{c}\text { Umidade } \\
(\%)\end{array}$ & $\begin{array}{c}\text { Lipídios } \\
\text { (\%) }\end{array}$ & $\begin{array}{l}\text { Acidez } \\
(\%)\end{array}$ \\
\hline 1 & 5,68 & 2,02 & 75 & 75 & 40,82 & 46 & 0,1966 \\
\hline 2 & 5,32 & 2,68 & $>1100$ & $>1100$ & 44,47 & 32 & 0,2037 \\
\hline 3 & 5,43 & Ausente & 1100 & $>1100$ & 56,20 & 32 & 0,3500 \\
\hline 4 & 5,32 & 2,62 & 460 & 1100 & 33,76 & 40 & 0,2507 \\
\hline 5 & 5,27 & 3,41 & 460 & 460 & 36,66 & 42 & 0,2439 \\
\hline 6 & 5,40 & 2,72 & 23 & 23 & 54,78 & 34 & 0,4175 \\
\hline 7 & 5,45 & 3,48 & $>1100$ & $>1100$ & 52,06 & 22 & 0,2994 \\
\hline 8 & 5,02 & 2,30 & $>1100$ & $>1100$ & 45,93 & 44 & 0,1935 \\
\hline 9 & 5,43 & 2,73 & 1100 & 1100 & 36,11 & 22 & 0,4235 \\
\hline 10 & 5,62 & 2,38 & $>1100$ & $>1100$ & 38,67 & 24 & 0,2649 \\
\hline 11 & 5,14 & Ausente & 1100 & 1100 & 57,75 & 30 & 0,4180 \\
\hline 12 & 5,43 & 2,58 & $>1100$ & 1100 & 34,66 & 48 & 0,4163 \\
\hline 13 & 5,34 & 3,48 & 460 & 240 & 42,22 & 32 & 0,2631 \\
\hline 14 & 5,36 & 3,04 & $>1100$ & $>1100$ & 38,87 & 36 & 0,2202 \\
\hline 15 & 5,16 & Ausente & 93 & 93 & 64,31 & 28 & 0,1487 \\
\hline 16 & 5,30 & 2,99 & 15 & 7,4 & 52,48 & 50 & 0,3817 \\
\hline 17 & 5,85 & 2,63 & Ausente & Ausente & 43,47 & 46 & 0,3386 \\
\hline 18 & 5,89 & 2,06 & Ausente & Ausente & 41,30 & 40 & 0,5059 \\
\hline 19 & 5,45 & 3,48 & $>1100$ & 290 & 46,57 & 48 & 0,2469 \\
\hline 20 & 5,22 & 3,12 & 11 & Ausente & 37,92 & 38 & 0,2900 \\
\hline 21 & 5,27 & 3,48 & Ausente & Ausente & 30,12 & 48 & 0,2964 \\
\hline 22 & 5,33 & 3,48 & 36 & 36 & 32,52 & 26 & 0,3486 \\
\hline 23 & 5,33 & 3,48 & 27 & 7,4 & 47,50 & 40 & 0,4125 \\
\hline 24 & 5,68 & 2,45 & 11 & 21 & 38,72 & 60 & 0,5869 \\
\hline 25 & 5,35 & 3,48 & 3,6 & Ausente & 33,80 & 48 & 0,4995 \\
\hline 26 & 5,30 & 2,67 & Ausente & Ausente & 51,98 & 38 & 0,6417 \\
\hline 27 & 5,24 & 2,67 & 1100 & 1100 & 53,19 & 22 & 0,5468 \\
\hline 28 & 5,26 & 3,48 & 23 & 23 & 46,08 & 30 & 0,5458 \\
\hline 29 & 5,31 & 3,03 & 93 & 93 & 38,78 & 50 & 0,5078 \\
\hline 30 & 5,26 & 1,88 & 23 & 23 & 51,42 & 36 & 0,4234 \\
\hline
\end{tabular}

Fonte: Elaboração dos autores.

O alto índice de $S$. aureus observado no presente estudo provavelmente está associado à manipulação inadequada durante a produção artesanal. Feitosa et al. (2003) estudaram a ocorrência de S. aureus em queijos de coalho e de manteiga produzidos de forma artesanal no Rio Grande do Norte e também verificaram a incidência deste patógeno na maioria das amostras analisadas, variando de $72,7 \%$ e 
$84,7 \%$, respectivamente, para queijo de coalho e o de manteiga.

$\mathrm{Na}$ determinação de NMP de coliformes totais, 16 amostras (53\%) apresentaram contagens dentro do permitido, ou seja, inferiores a $10^{2} \mathrm{NMP} / \mathrm{g}$, enquanto 14 amostras (47\%) apresentaram contagens elevadas, que chegaram a valores superiores a $1,1 \times 10^{3} \mathrm{NMP} / \mathrm{g}$. O limite de coliformes termotolerantes neste produto é de $10 \mathrm{NMP} / \mathrm{g}$, os resultados variaram de 0 a valores superiores à $1,1 \times 10^{3} \mathrm{NMP} / \mathrm{g}$, portanto $73 \%$ estavam fora dos padrões estabelecidos pela legislação vigente (Tabela 1). Os coliformes totais são micro-organismos pertencentes à família Enterobacteriaceae representados pelos gêneros Escherichia, Enterobacter, Citrobacter Klebsiella, que apresentam a capacidade de fermentar lactose produzindo ácido lático e gás quando incubadas a 35-37 $\mathrm{C}$. Estes micro-organismos são considerados indicadores de higiene, sendo usados para avaliar condições higiênico-sanitárias ou processamento de um alimento. São sensíveis à temperatura de pasteurização e sua presença em produtos tratados termicamente indica contaminação pósprocessamento (LUND et al., 2007). Vários estudos vêm demonstrando a presença de coliformes em produtos lácteos. Feitosa et al. (2003) encontraram coliformes totais em todas as amostras de queijos, produzidos no Rio Grande do Norte, analisadas em seu estudo e coliformes termotolerantes em $36 \%$ do total.

A baixa qualidade microbiológica das amostras avaliadas no presente estudo reflete as condições precárias adotadas na elaboração de produtos alimentícios artesanais, com ausência da adoção de BPF exigidas pela Agencia Nacional de Vigilância Sanitária e Ministério da Agricultura (BRASIL 1997a, 1997b). Quando os alimentos não são fabricados em acordo com as BPF podem constituir perigo à saúde do consumidor (DESTRI et al., 2009). Pereira et al. (1999) citam que fatores como temperatura inadequada, incorretas condições de manufatura e armazenagem, contribuem também de forma efetiva para o comprometimento da qualidade do produto final. Silva et al. (2010) demonstraram que ao se elaborar um derivado lácteo seguindo as boas práticas de fabricação, obtém-se um produto inócuo e que não oferece riscos a saúde do consumidor.

Outros autores também reportam baixa qualidade microbiológica de produtos alimentícios produzidos de forma artesanal. Almeida et al. (2009) avaliaram a qualidade microbiológica de alimentos artesanais produzidos na Região do Alto Jequitinhonha e também detectaram baixa qualidade microbiológica nos parâmetros de aeróbios mesófilos, S. aureus e coliformes totais e termotolerantes. Loguercio e Aleixo (2001) estudaram a microbiologia do queijo minas frescal produzidos artesanalmente, e correlacionaram a aplicação ou não das Boas Práticas com os resultados das contagens microbiológicas dos queijos avaliados. Estes autores verificaram que um percentual de $93,33 \%$ e $96,67 \%$ das amostras apresentou-se em desconformidade com os padrões exigidos pela legislação brasileira para $S$. aureus e coliformes fecais, respectivamente. Soares et al. (2009) reportam a baixa qualidade microbiológica de manteigas de garrafa produzidas artesanalmente na cidade de Mossoró-RN. Feitosa et al. (2003) verificaram a baixa qualidade microbiológica de queijos produzidos artesanalmente no estado do Rio Grande do Norte.

Em contrapartida, Destrietal.(2009) encontraram resultados distintos dos encontrados no presente estudo, ao avaliarem a qualidade das amostras de doce de leite artesanais comercializados na cidade de Pelotas, e verificarem que $100 \%$ dos doces possuíam qualidade microbiológica satisfatória quanto à presença de $S$. aureus e coliformes a $45^{\circ} \mathrm{C}$, possivelmente pelo fato deste produto apresentar atividade de água incompatível com o crescimento destes micro-organismos.

Observou-se uma variação de 30,15 a 57,75\% no teor de umidade das amostras. $\mathrm{O}$ teor de gordura dos cremes variou de 22 a $60 \%$ (Tabela 1). O 
regulamento de identidade e qualidade do creme de leite classifica este produto quanto ao teor de gordura e preconiza um teor de gordura de no mínimo $10 \%$, enquanto que o valor máximo não está especificado no regulamento (BRASIL, 1996). Em nenhuma das amostras analisadas, verificou-se teor de gordura abaixo de $10 \%$, portanto as mesmas obtiveram resultados satisfatórios neste parâmetro de qualidade. Observou-se que, do total de amostras avaliadas, nenhuma pode ser classificada como "creme com baixo teor de gordura" (10 a 19,9\% de gordura), e que a grande maioria (90\%) se enquadra na categoria de "creme" (20 a 49,9\% de gordura), enquanto apenas três amostras foram classificadas como "creme com elevado teor de gordura" (mínimo 50\% de gordura). Stephani et al. (2011) avaliaram o teor de gordura de cremes de leite UHT comercializados no Brasil e observaram que todas a amostram estavam de acordo com a legislação brasileira. Estes autores encontraram valores semelhantes ao presente estudo, ou seja, nenhum dos produtos apresentou teor de gordura inferior a $10 \%$ e a média foi de $20,3 \%$.

Ao contrário do que exige o Regulamento Técnico de Identidade e Qualidade de creme de leite, nenhuma das amostras avaliadas no presente estudo especificou através de rótulo o tipo de creme de leite em relação ao teor de gordura (creme leve, creme e creme com elevado teor de gordura), o que é uma exigência da legislação em vigor.

A maioria das amostras (90\%) apresentou valores acima do permitido pela legislação em vigor para a acidez (máximo 0,20g de ácido lático em $100 \mathrm{~g}$ de creme). A acidez elevada é um indicativo de contaminação por micro-organismos fermentadores da lactose em ácido lático ou até mesmo comercialização do produto além da vida de prateleira, o que se torna preocupante do ponto de vista de saúde pública. Ribeiro Júnior et al. (2012) avaliaram a acidez de cremes de leites UHT e verificaram que todas as amostras estavam de acordo com a legislação brasileira quanto a acidez, o que demonstra que tratamento térmico elimina os micro-organsimos e, consequentemente, mantém a acidez do produto estável.

Os cremes de leite artesanais avaliados possuem baixa qualidade microbiológica, portanto, são impróprios ao consumo humano. Quanto aos parâmetros físico-químicos, o teor de gordura estava dentro dos padrões exigidos pela legislação, enquanto que para o parâmetro de acidez titulável, a maioria das amostras analisadas obteve valores elevados. Este produto apresentou-se fora dos padrões exigidos pela legislação quanto à rotulagem, que segundo a legislação brasileira em vigor é obrigatória e o rótulo deve informar o tipo de creme de leite quanto ao teor de gordura.

Observa-se, portanto, a necessidade de inspeção da matéria prima e adoção de boas práticas de fabricação (BPF) para produção do creme de leite artesanal, visando agregação de valor aos produtos e segurança alimentar para os consumidores.

\section{Referências}

ALMEIDA, A. C.; PINHO, L.; SOBRINHO, E. M.; MORAIS, H. A.; ALMEIDA, H. C.; SANTOS, E. N.; MURTA, N. M. G.; SANTOS, R. A.; DIAS, A. C. P. Qualidade sanitária de alimentos artesanais produzidos na Região do Alto Jequitinhonha, Higiene Alimentar, São Paulo, v. 23, n. 170-171, p. 47-52, 2009.

ALMEIDA, R. C. C.; KUAYE, A. Y.; SERRANO, A. M.; ALMEIDA, P. F. Avaliaçäo e controle da qualidade microbiológica de mäos de manipuladores de alimentos. Revista de Saúde Pública, São Paulo, v. 29, n. 4, p. 290294, 1995.

ASSOCIATION OF ANALYTICAL CHEMISTS AOAC. Official methods of analysis of the association of official analytical chemists. 15. ed. Washington: AOAC, 1990.

BALBINI, A. P. S.; BUTUGAN, O. Biological food contamination. Revista de Pediatria, São Paulo, v. 23, p. 320-328, 2001.

BRASIL. Portaria n 368, de 04 de setembro de 1997. Aprova o regulamento técnico sobre as condições higiênico-sanitárias e de boas práticas de fabricação para estabelecimentos elaboradores/industrializadores de alimentos. Diário Oficial [da] União, Brasília, DF, 08 set. 1997a. Seção 1, p. 19697-19699. 
Portaria ${ }^{\circ} 326$, de 30 de julho de 1997. Estabelece regulamento técnico condições higiênico-sanitárias e de boas práticas de fabricação para estabelecimentos produtores/industrializadores de alimentos. Diário Oficial [da] União, Brasília, DF, 01 ago. 1997b. Seção 1, p. 16560-16563.

Ministério da Agricultura, Pecuária e Abastecimento. Instrução Normativa $\mathrm{N}^{\circ} 62$, de 26 de agosto de 2003. Oficializa os métodos analíticos oficiais para análises microbiológicas para controle de produtos de origem animal e água. Diário Oficial [da] União, Brasília, 26 ago. 2003. Seção 1. p. 14.

. Portaria No 146, de 07 de março de 1996. Aprova os regulamentos técnicos de identidade e qualidade dos produtos lácteos. Anexo IV: regulamento técnico de identidade e qualidade de creme de leite. Diário Oficial [da] União, Brasília, DF, 11 de mar. de 1996. Seção 1, p. 3980-3981.

BRITISH STANDARDS INSTITUTION - BSI. Determination of fat content of milk and milk products (Gerber method). Methods. London: British Standards Institution, 1989. $12 \mathrm{p}$.

DESTRI, K.; BAIRROS, J.; VARGAS, B. L.; NASCENTE, P. S. DEL PINO, F. A. B.; LUND, R. G. Análise microbiológica de doces de leite vendidos em feiras livres de Pelotas, Estado do Rio Grande do Sul. Acta Scientiarum, Maringá, v. 31, n. 2, p. 153-157, 2009.

DUARTE, D. A. M.; SCHUCH, D. M. T.; SANTOS, S. B.; RIBEIRO, A. R. Pesquisa de Listeria monocytogenes e microrganismos indicadores de higiênico-sanitários em queijo de coalho produzido e comercializado no Estado de Pernambuco. Arquivos do Instituto Biológico, São Paulo, v. 72, n. 3, p. 297-302, 2005.

FEITOSA, T.; BORGES, M. F.; NASSU, R. T.; AZEVEDO, E. H. F.; MUNIZ, C. R. Pesquisa de salmonella sp., listeria sp. e microrganismos indicadores higiênico-sanitários em queijos produzidos no estado do Rio Grande do Norte. Ciência e Tecnologia de Alimentos, Campinas, v. 23, p. 162-165, 2003. Suplemento.

GERMANO, P. M. L.; GERMANO, P. M. L. Higiene e vigilância sanitária de alimentos. 3. ed. São Paulo: Manole, 2008. 986 p.

GONÇALVES, E. C. B. A. Análise de alimentos: uma visão química da nutrição. 3. ed. São Paulo: Varela, 2012. $324 \mathrm{p}$.

JAY, J. M. Microbiologia de alimentos. 6. ed. Porto Alegre: Artmed, 2005. $711 \mathrm{p}$.
LOGUERCIO, A. P.; ALEIXO, J. A. G. Microbiologia de queijos tipo minas frescal produzido artesanalmente. Ciência Rural, Santa Maria, v. 31, n. 6, p. 1063-1064, 2001.

LUND, D. G.; ZAICOVSKI, C. D.; PRIETO, L. M.; CONCEIÇÃO, R. C. S.; ALEIXO, J. A. G.; ROMBALDI, C. V. Qualidade microbiana e aspecto visual de mandioca minimamente processada. Acta Scientiarum, Maringá, v. 29, n. 2, p. 213-216, 2007.

MORTATTI, M. P. L.; ZAVARIZE, A. C. M.; OUTUKA, M. S.; SILVA K. C.; MATIAZI, H. J.; LEITE K. M. C. Avaliação microbiológica de doces cremosos comercializados na cidade de Araraquara-SP. Alimentos e Nutrição, Araraquara, v. 4, n. 1, p. 89-97, 1992.

ORDONEZ, J. A. Tecnologia de alimentos: componentes dos alimentos e processos. Porto Alegre: Artmed, 2005. v. 1, $294 \mathrm{p}$.

PEREIRA, M. L.; GASTELOIS, M. C. A.; BASTOS, E. M. A. F.; CAIAFFA, W. T.; FALEIRO, E. S. C. Enumeração de coliformes fecais e presença de Salmonella sp. em queijo minas. Arquivo Brasileiro de Medicina Veterinária e Zootecnia, Belo Horizonte, v. 51, n. 5 , p. 427-431, 1999.

PINTO, C. L. O.; MARTINS, M. L.; VANETTI, M. C. D. Qualidade microbiológica de leite cru refrigerado e isolamento de bactérias psicrotróficas proteolíticas. Ciência e Tecnologia de Alimentos, Campinas, v. 26, n. 3, p. 645-651, 2006.

RIBEIRO JÚNIOR, J. C.; BETOLI, V.; TAMANINI, R.; SILVA, L. C. C. Avaliação da qualidade físico-química e microbiológica de cremes de leite UHT. Revista do Instituto de Laticínios Cândido Tostes, Juiz de Fora, v. 67, n. 385, p. 31-37, 2012.

SILVA, E. V. C.; MEDEIROS, L F. P. S.; MONTEIRO, D. B.; SILVA, G. F. Elaboração de bebida láctea pasteurizada sabor bacuri enriquecida com pólen, Revista Brasileira de Tecnologia Agroindustrial, Ponta Grossa, v. 4, n. 1, p. 1-9, 2010.

SOARES, K. M. P.; AROUCHA, E. M. M.; GÓIS, V. A.; ABRANTES, M. R.; ROCHA, M. O. C.; SILVA, J. B. A. Avaliação da qualidade microbiológica de manteigas de garrafa comercializadas no município de Mossoró, RN. Acta Veterinaria Brasilica, Mossoró, v. 3, n. 3, p. 143146, 2009.

STEPHANI, R.; NEVES, H. C.; NEVES, E. O.; SOUZA, A. B.; PERRONE, I. T.; SILVA, P. H. F. Caracterização físico-química do creme de leite UHT comercializado no Brasil. Revista do Instituto de Laticínios Cândido Tostes, Juiz de Fora, v. 66, n. 379, p. 25-29, 2011. 
